\title{
Peningkatan Ketrampilan Ibu-Ibu Pengajian Dalam Kepatuhan Penatalaksanaan Hipertensi
}

\author{
Raditya Kurniawan Djoar', Anastasia Putu Martha Anggarani ${ }^{2}$ \\ ${ }^{1}$ STIKES Katolik St.Vincentius a Paulo Surabaya. \\ email: radit_stikvinct@yahoo.com \\ ${ }^{2}$ STIKES Katolik St.Vincentius a Paulo Surabaya. \\ email: anastasiamartha@yahoo.co.id
}

\begin{abstract}
Abstrak
Hipertensi juga dikenal dengan sebutan "pembunuh diam-diam", dimana penderita tidak menunjukkan gejala khusus, tetapi bisa menjadi pemicu utama stroke, penyakit jantung, serta penyakit ginjal kronik apabila tidak dilakukan pemantauan yang baik. Karena tidak memiliki gejala yang khas, seringkali masyarakat tidak terlalu memedulikan untuk penatalaksanaan terkait hipertensi. Fenomena yang terjadi dimasyarakat didapatkan bahwa penderita hiperteni seringkali menghentikan pengobatan atau tidak patuh apabila sudah tidak merasakan gejala, sedangakan secara teori pegobatan hipertensi harus dilakukan seumur hidup. Metode yang dilakukan adalah koordinasi dengan ketua perkumpulan, melakukan pertemuan dengan ibu untuk menyampaikan maksud dan tujuan kegiatan, pemberian materi, tanya jawab dengan audience, evaluasi (feed back) setelah dilakukan kegiatan. Tingkat pengetahuan Ibu-ibu sebelum penyuluhan yaitu tingkat pengetahuan kurang $64 \%$ responden, tingkat pengetahuan cukup $25 \%$ responden dan pengetahuan baik didapatkan pada $11 \%$ responden. Tingkat pengetahuan didapatkan sesudah dilakukan penyuluhan kesehatan terjadi peningkatan pengetahuan dimana terdapat $83 \%$ responden didapatkan nilai pengetahuan baik, $17 \%$ responden pengetahuan cukup dan tidak terdapat responden yang didapati tingkat pengetahuan kurang. Saran kegiatan ini adalah memotivasi ibu-ibu untuk aktif mengikuti pendidikan kesehatan untuk menambah pengetahuan mengenai kesehatan terutama penyakit-penyakit pada usia senja dan menerapkan cara pencegahan supaya tidak mengalami hipertensi, dan kalaupun sudah mengalami hipertensi dapat mengikuti penatalaksanaan yang baik.
\end{abstract}

Kata Kunci: Kepatuhan; Ibu ; Hipertensi

\section{Abstract}

Hypertension is also known as the "silent killer", where the patient does not show special symptoms, but can be a major trigger for stroke, heart disease, and chronic kidney disease if good monitoring is not done. Because it does not have distinctive symptoms, people often do not really care about hypertension-related management. The phenomenon that occurs in the community is that hypertension sufferers often stop treatment or do not comply when they have no symptoms, while in theory, hypertension treatment must be carried out for life. The method used is coordination with the head of the association, holding meetings with mothers to convey the aims and objectives of the activity, providing materials, asking and answering questions with the audience, evaluating (feed back) after the activity is carried out. The level of knowledge of mothers before counseling was $64 \%$ of respondents lacking knowledge, $25 \%$ of respondents had sufficient knowledge and $11 \%$ of respondents had good

\section{http://ejournal.urindo.ac.id/index.php/PAMAS}

Article History : 
knowledge. The level of knowledge obtained after health education was carried out, there was an increase in knowledge where $83 \%$ of respondents obtained good knowledge scores, $17 \%$ of respondents had sufficient knowledge and there were no respondents who found that their level of knowledge was lacking. The suggestion for this activity is to motivate mothers to actively participate in health education to increase knowledge about health, especially diseases in old age and to implement prevention methods so that they do not experience hypertension, and even if they already have hypertension, they can follow good management.

Keywords: Compliance; Mother ; Hypertension

\section{PENDAHULUAN}

Tekanan darah adalah tekanan yang dikeluarkan darah terhadap dinding arteri. Kelebihan tekanan pada bagian arteri di sirkulasi sistemik dapat menyebabkan penyakit yang disebut hiperaatensi (LeMone, Burke, \& Bauldoff, 2016). Hipertensi adalah perubahan tekanan darah dimana diastolik atau sistolik lebih dari batas normal (Billota, 2011). Secara umum dibedakan menjadi dua yaitu hipertensi esensial (primer) yang merupakan kondisi tersering yang ditemukan dan hipertensi sekunder, yang disebabkan penyakit renal atau penyakit lain yang dapat diidentifikasi (Kowalak, Welsh, \& Mayer, 2011). Menurut Prasetyaningrum (2014) Hipertensi juga dikenal dengan sebutan "pembunuh diam-diam", dimana penderita tidak menunjukkan gejala khusus, tetapi bisa menjadi pemicu utama stroke, penyakit jantung, serta penyakit ginjal kronik apabila tidak dilakukan pemantauan yang baik. Karena tidak memiliki gejala yang khas, seringkali masyarakat tidak terlalu memedulikan untuk penatalaksanaan terkait hipertensi. Fenomena yang terjadi dimasyarakat didapatkan bahwa penderita hiperteni seringkali menghentikan pengobatan atau tidak patuh apabila sudah tidak merasakan gejala, sedangakan secara teori pegobatan hipertensi harus dilakukan seumur hidup.

Menurut Kementerian Kesehatan (2014) hipertensi termasuk penyakit yang sering terjadi pada lansia dan menduduki posisi pertama dengan prevalensi sebesar 45,9 \% untuk kelompok umur 55 tahun sampai dengan 64 tahun, 57,6\% untuk kelompok umur 65 tahun sampai dengan 74 tahun dan 63,8 \% untuk usia diatas 75 tahun. Di Surabaya sendiri penderita hipertensi mencapai 137, 337 jiwa (16, 78\%) (Dinas Kesehatan, 2015). Berdasarkan penelitian sebelumnya menunjukan bahwa, $80 \%$ keluarga mengatakan jarang mengantar untuk mengontrol tekanan darahnya, $75 \%$ mengatakan membiarkan minum obat sendiri dan jarang diingatkan untuk minum obat, 62\% keluarga membiarkan untuk makan apapun yang disukainya dan juga tidak pernah membedakan makanan yang disediakan untuk keluarga maupun untuk lansia. Kondisi tersebut menggambarkan bagaimana kepatuhan dari penderita hipertensi (Budiman., \& Riyanto, A, 2014) . 
Menurut Prasetyaningrum (2014) kepatuhan dalam pengelolaan penyakit hipertensi sesuai pedoman yang terstandart dapat membantu proses pencegahan atau penundaan terjadinya masalah kesehatan akibat hipertensi. Pengelolaan penyakit hipertensi oleh penderita dapat berupa modifikasi gaya hidup menjadi perilaku yang sehat, seperti diet makanan yang sesuai, olahraga teratur, minum obat secara teratur, control tekanan darah.

Dalam memodifikasi gaya hidup, meningkatkan pengetahuan dan kesadaran keluarga sangat penting dalam hal perawatan kesehatan dan juga mendukung penderita hipertensi untuk mempertahankan kesehatan dan pengontrolan tekanan darah (Asikin, 2016).

\section{METODE PELAKSANAAN}

Metode Pengabdian Masyarakat yang dilakukan adalah koordinasi dengan ketua perkumpulan, melakukan pertemuan dengan ibu untuk menyampaikan maksud dan tujuan kegiatan, pemberian materi menggunakan leaflet yang akan disimpan para ibu, tanya jawab dengan audience tentang materi yang diberikan, implementasi praktik oleh para ibu paguyuban mengenai hipertensi dan pengukurannya, evaluasi (feed back) setelah dilakukan kegiatan

\section{HASIL DAN PEMBAHASAN}

Mengawali kegiatan pengabdian masyarakat dimulai dengan persiapan pelaksana yaitu melakukan persiapan kebutuhan peralat yang akan digunakan yaitu leafleat dan menghubungi. Persiapan dimulai pukul 18.00 WIB untuk mempersiapkan pelaksanaan kegiatan. Penyuluhan dilakukan dengan cara presentasi oleh pelaksana dan dengan alat bantu leaflet. Kegiatan ini dilaksanakan pada hari Kamis, 28-11-2019 pukul 19.30 WIB sampai dengan jam 20.00 WIB. Sebelum dan setelah dilakukan penyuluhan, peserta diberi kuesioner mengenai tingkat pengetahuan tentang penatalaksanaan Hipertensi.

Hasil kegiatan ini didapatkan 67 ibu-ibu yang hadir pada kegiatan dan mengikuti penyuluhan. Adapun hasil tingkat pengetahuan sebelum penyuluhan adalah: 


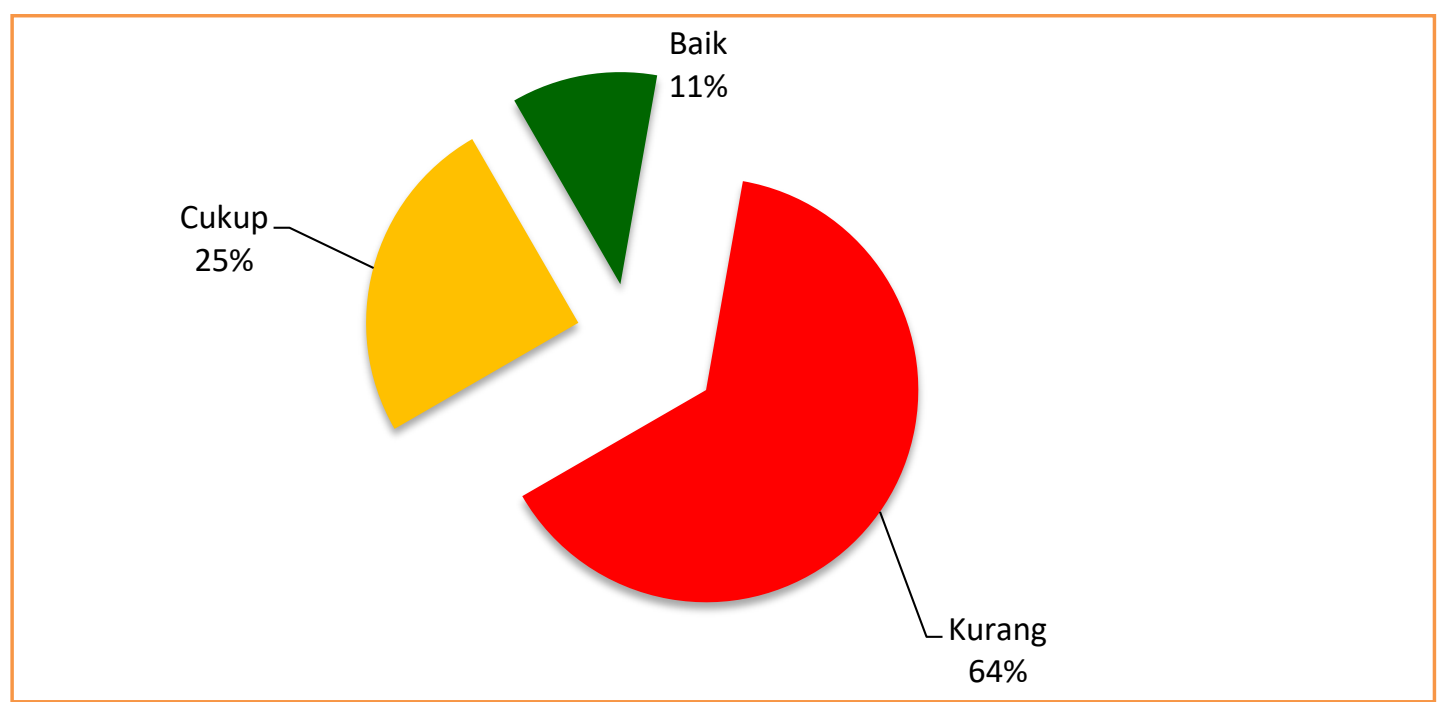

Gambar 1 Tingkat Pengetahuan Ibu-ibu Tentang Penatalaksanaan Hipertensi Dasar Sebelum

Pelaksanaan Kegiatan

Tingkat pengetahuan sebelum penyuluhan yaitu tingkat pengetahuan kurang 43 responden, tingkat pengetahuan cukup 16 responden dan tingkat pengetahuan baik sebanyak 8 responden.

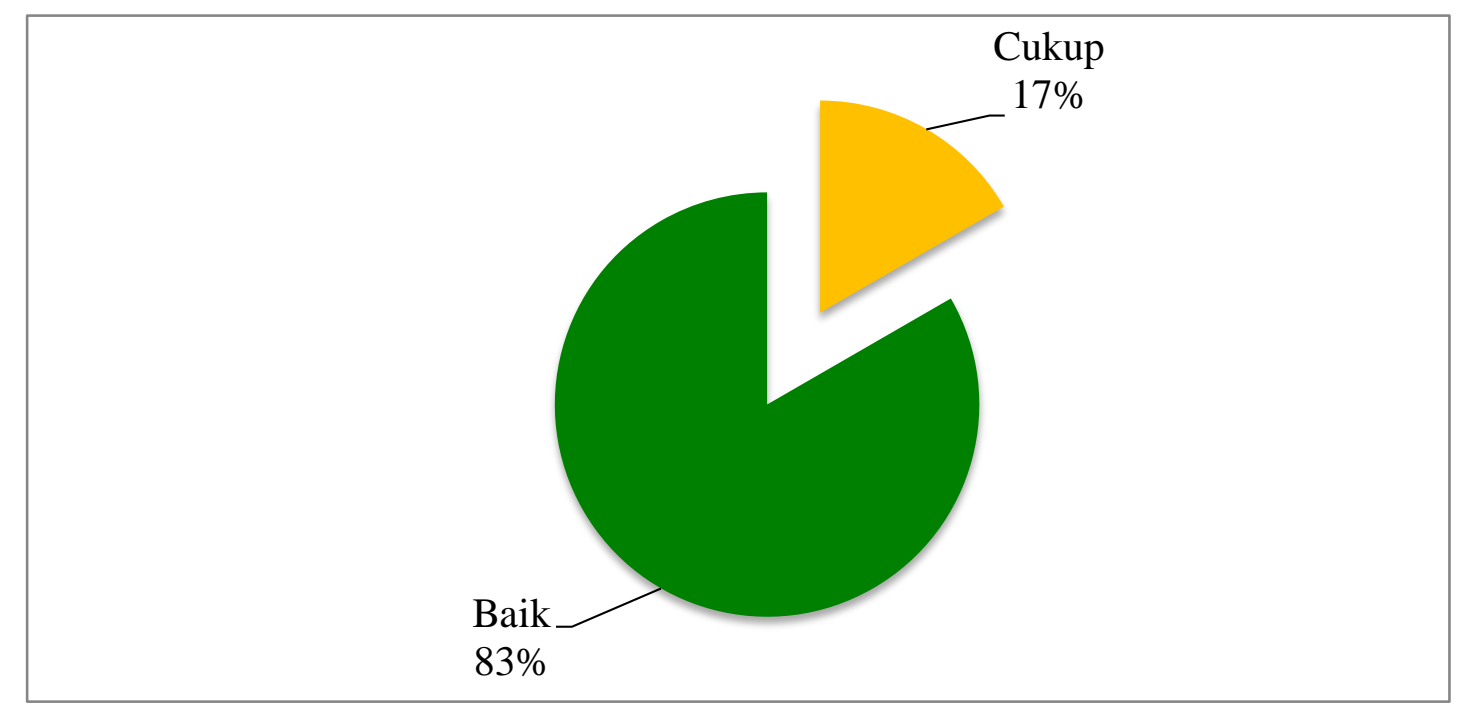

Gambar 2 Tingkat Pengetahuan Ibu-ibu PKK Tentang Kejadian Ikutan Pasca Imunisasi Dasar

Setelah Pelaksanaan Kegiatan

Tingkat pengetahuan didapatkan sesudah dilakukan penyuluhan kesehatan terjadi peningkatan pengetahuan dimana terdapat 57 responden dengan kriteria pengetahuan baik, 10 responden dengan kriteria pengetahuan cukup, serta tidak terdapat responden yang memiliki tingkat pengetahuan kurang. 
Menurut (Mubarak, 2012), pengalaman merupakan suatu aktivitas yang dialami seseorang saat sedang berinteraksi dengan lingkungannya pada waktu yang lampau. Pengalaman tidak selalu soal pengalaman yang baik tetapi juga bisa pengalaman yang kurang baik. Kebanyakan orang akan mengingat dengan baik pengalaman mereka yang baik dan cenderung melupakan pengalaman mereka yang kurang baik (Ulya, I.,2015). Pengalaman baik yang dialami seorang kerap kali menimbulkan kesan yang baik dan mendalam (Ramadhan, A. J.,2010). Kesan yang baik dan mendalam tersebut akan membentuk sikap positif dalam hidupnya. Pada bagian ini akan ditunjukkan bagaimana pengalaman yang baik menimbulkan kesan yang baik dan membentuk sikap positif bagi seseorang .

Berdasarkan hasil pendataan sesudah dilakukan penyuluhan, dari 67 responden, 57 (83\%) responden berada pada kriteria pengetahuan baik dan $10(17 \%)$ responden pada kriteria pengetahuan cukup. Hal ini sangat dimungkinkan terjadi sebab rata-rata responden memiliki riwayat Hipertensi dan juga anggota keluarga mereka ada yang menderita hipertensi, sehingga dengan mudah mereka menerapkan dan menerimanya informasi yang berkaitan dengan penatalaksanaan hipertensi seperti bagaimana pengobatan, diet, kontrol dan aktivitas pada penderita hipertensi (Sutrisno, R. S., \& Setyowati, U.,2013). Pada akhirnya pengalaman positif tadi dapat memberikan pengetahuan yang baik dan membuat responden mampu menjawab pertanyaan tentang penatalaksanaan hipertensi (Triariningrum, D., \& Sukihananto.,2013).

\section{KESIMPULAN}

Kesimpulan dari kegiatan ini adalah tingkat pengetahuan Ibu-ibu sebelum penyuluhan yaitu tingkat pengetahuan kurang 8 orang responden, kriteria pengetahuan cukup 16 orang dan tingkat pengetahuan baik sebanyak 43 orang responden. Tingkat pengetahuan didapatkan sesudah dilakukan penyuluhan kesehatan terjadi peningkatan pengetahuan dimana terdapat 57 responden memiliki tingkat pengetahuan baik, 10 orang responden dengan kriteria pengetahuan cukup dan tidak terdapat ada yang berada pada kriteria pengetahuan kurang.

Sarannya, memotivasi ibu-ibu untuk aktif mengikuti pendidikan kesehatan untuk menambah pengetahuan mengenai kesehatan terutama penyakit-penyakit pada usia senja dan menerapkan cara pencegahan supaya tidak mengalami hipertensi, dan kalaupun sudah mengalami hipertensi dapat mengikuti penatalaksanaan yang baik. 


\section{UCAPAN TERIMA KASIH(Jikadiperlukan)}

Kegiatan ini sepenuhnya dibiayai oleh Sekolah Tinggi Ilmu Kesehatan Katolik St. Vincentius a Paulo Surabaya.

\section{DAFTAR RUJUKAN}

Asikin, M., Nuralamsyah, M., \& Susaldi. (2016). Keperawatan Medikal Bedah Sistem Kardiovaskular. Jakarta: Erlangga.

Bilotta, K. A. J. (2011). Kapita Selekta Penyakit: Dengan Implikasi Keperawatan. Jakarta: EGC.

Budiman., \& Riyanto, A (2014). Kapita Selekta Kuesioner Pengetahuan dan Sikap dalam Penelitian Kesehatan. Jakarta: Salemba Medika.

Fitriani, S. (2011). Promosi Kesehatan. Yogyakarta: Graha Ilmu.

Friedman, M. M., Bowden, V. R., \& Jones, E. G. (2010). Buku Ajar Keperawatan Keluarga Riset, Teori \& Praktik. Jakarta: EGC.

Kowalak, J. P., Welsh, W., \& Mayer, B. (2011). Buku Ajar Patofisiologi. Jakarta: EGC.

Kementerian Kesehatan. (2014). Infodatin Situasi dan Analisis Lanjut Usia. Retrieved from http://www.pusdatin.kemkes.go.id/resources/download/pusdatin/infodatin/infodatinlansia.pdf

LeMone, P., Burke, K. M., \& Bauldoff, G. (2016). buku ajar keperawatan medikal bedah: Gangguan Eliminasi, Gangguan Kardiovskular (5th ed.). Jakarta: EGC.

Mubarak, W. I. (2012). Promosi Kesehatan Untuk Kebidanan. Jakarta: Salemba Medika.

Prasetyaningrum, Y. I. (2014). Hipertensi Bukan untuk Ditakuti. Jakarta: FMedia.

Ramadhan, A. J. (2010). Mencermati Berbagai Gangguan pada Darah dan Pembuluh Darah. Yogyakarta: Diva Press.

Sutrisno, R. S., \& Setyowati, U. (2013). Jangan Panik Saat Anak Sakit. Yogyakarta: Trans Idea Publishing.

Triariningrum, D., \& Sukihananto. (2013). Pelaksanaan Tugas Kesehatan Keluarga Pada Keluarga Dengan Hipertensi. FIK UI. Retrieved from http://lib.ui.ac.id/naskahringkas/2015-08/S46414-Diyatmi Triariningrum 
Jurnal Pelayanan dan Pengabdian Masyarakat (PAMAS)

Ulya, I. (2015). Tugas kesehatan keluarga mengenal diet hipertensi pada lansia. Jurnal IImu Keperawatan, 5(1), 91-99. Retrieved from download.portalgaruda.org/article.php 